\title{
Sperm Donation in IUI and Preeclampsia's Risk: Case of Reoccurrence in Patient with the Same Donor
}

\author{
C. S. Kamto Fotso ${ }^{1}$, Saidi S. Dahman ${ }^{2}$ and K. F. Kenfack ${ }^{3}$ \\ 1. Clinique de Fertilité, Département de Gynécologie et Obstétrique, Hôpital Erasme, -1070 Bruxelles, Belgique; Maternité des Dix \\ Lunes,Service de Gynécologie et Obstétrique, Centre Hospitalier EpiCURA_Site d'Ath, 7800 Ath, Belgique \\ 2. CHU, Brugmann Site Horta, Département de Gynécologie et Obstétrique. Clinique des Grossessses à Haut Risque, 1020 Bruxelles, \\ Belgique \\ 3. Centre Médical Colbert-Service de Maternité, Douala, Cameroon
}

\begin{abstract}
Preeclampsia remains a major obstetrical problem, affecting 3-5\% of pregnancies and can be up to $18 \%$ in some African countries. Epidemiological studies based on the immune theory showed the relationship between exposition to sperm and preeclampsia. Repeated exposition to seminal liquid would therefore be a protection against preeclampsia, as observed in women having frequent unprotected sex, or having had a previous normal pregnancy with the same partner. Other publications showed an increased risk of preeclampsia in patients who received sperm during an intrauterine insemination (IUI) or during an in vitro fertilization (IVF). We report a case of reoccurrence of severe preeclampsia in a mixed afro-caucasian couple having had a child delivered normally at term in the past. The couple later went for a sperm donation as a result of a chemotherapeutic treatment for Hodgkin Lymphoma which the man suffered from. The fact that the sperm was gotten from the same donor did not stop the reoccurrence. The first pregnancy gotten from sperm donation ended up into a medical termination of pregnancy (MTP) at 23 weeks 2 days of amenorrhea, and the second pregnancy issued from the same donor ended into a cesarean delivery at 28 weeks of a child with intrauterine growth retardation (IUGR).
\end{abstract}

Key words: Sperm donor and pre-eclampsia, IIU and pre-eclampsia.

\section{Introduction}

Preeclampsia remains a major obstetrical problem, affecting 3-5\% of pregnancies and can reach up to $18 \%$ in some countries $[1,2]$.

Though its pathophysiological mechanism is not well described, it is characterized by an abnormal vascular response to placentation, coupled with an increase in systemic vascular resistance, platelet aggregation, activation of the coagulation system, and an endothelial dysfunction [1].

Epidemiological studies based on immune theory showed a relationship between exposition to sperm and pre-eclampsia [3, 4]. Repeated exposition to

Corresponding author: Kamto Fotso Christian, MD, Master en Management des Institutions de Soins et de Santé, research fields: gynecology, obstetric, fertility, hospital management. seminal liquid would therefore be a protection against pre-eclampsia as observed in women having frequent unprotected sexual intercourse, or having had a previous normal pregnancy with the same partner [5-8].

Many studies have shown an increased risk of pre-eclampsia in patients receiving sperm during an intrauterine insemination (IUI) or during in vitro fertilization (IVF) $[1,9,10]$. We report a case of reoccurrence of severe pre-eclampsia in a mixed afro-caucasian couple having had a child delivered normally at term in the past. The couple later went for a sperm donation resulting from a chemotherapeutic treatment for Hodgkin Lymphoma which the man suffered from. The fact that the sperm was gotten from the same donor did not stop the reoccurrence.

The first pregnancy gotten from sperm donation 
ended up into a medical termination of pregnancy (MTP) at 23 weeks 2 days of amenorrhea, and the second pregnancy issued by the same donor ended into a cesarean delivery at 28 weeks of a child with intrauterine growth retardation (IUGR).

\section{Case Study}

A 32 years old African patient married to a caucasian; Gravida: 1, Para: 1 at the time of contact having had a normal delivery at term, of a boy weighing 4,010 g, in February 2010.

Menarche at 13 years, regular cycles. Weight: $95 \mathrm{~kg}$ height $175 \mathrm{~cm}$; BMI: $31 \mathrm{~kg} / \mathrm{m}^{2}$.

In her personal history, we note a lateral right uterine myoma measuring $35 \mathrm{~mm}$ in its long axis, rated type 6 in the FIGO classification.

In her family history, mother died at 36 of a breast cancer.

The patient is blood group A+, normal electrophoresis, blood sugar $81 \mathrm{mg} / \mathrm{dL}$. She is immunized for Toxoplasmosis, Rubeola, Cytomegalovirus, and the Epstein-Barr virus; her serologies are negative for hepatitis B and C, Syphilis and HIV.

In her husband's past history, we mainly note a stage 4 sclero-nodular Hodgkin lymphoma in October 2007.

Given the fact that the chemotherapeutical treatment administered was not declared gonadotoxic by the Oncological Multidisciplinary Concertation, no cryoconversion of sperm was conducted.

In August 2010, her husband sustained an abdominal reoccurence for which he obtained a more aggressive catch-up treatment, then an autograft of the stem cells in may 2015.

Following these treatments, the spermogram of the man showed azoospermia, even after centrifugation.

After discussion with the couple, it was agreed to conduct intrauterine inseminations with anonymous sperm donation.

Between March 2015 and June 2015, the couple had 4 cycles of IUI, with the same donor, all ending up into failures.

At the 5th IUI, the donor was changed and she gets pregnant at the 6th IUI with this donor in September 2015.

The 1st trimester of her pregnancy is without any incident, if not for a combined risk of severe preeclampsia on the 1st trimester ultrasound (Fig. 1).

On the 2nd trimester ultrasound, an IUGR is noticed with a bilateral pathological uterine notching. Blood pressure: 160/90-150/90 mmHg urine dipstick showing proteins 2+. Biology: Platelets at 159000, APTT increased at 37.7; increased ALT, 40. The rest was normal (Fig. 2).

The patient is admitted, and a treatment consisting of Labetalol $200 \mathrm{mg}, 3$ times daily is initiated.

The blood pressure is poorly controlled, and the patient becomes symptomatic with headache, scotoma, lower limb edema with the increased proteinuria at 3.4 $\mathrm{g} / 24 \mathrm{~h}$.

A medical termination of pregnancy is then suggested to the couple according to the Fetocide + myfegine and cytotec protocole. Then childbirth occurs at 23 weeks and 2 days of the pregnancy; a girl of 309 grams in weight and 24.5 centimeters in height was born.

In June 2016, she underwent another IUI using the sperm of the donor of the previous pregnancy. She is placed on cardioaspirin $100 \mathrm{mg}$ from the day of the IUI, so as to reduce the risk of preeclampsia. She gets pregnant, and the same manifestations of preeclapmsia begin as from the 2nd trimester ultrasound (IUGR, pathologic uterine Dopplers) (Fig. 4).

The patient refuses a medical termination of pregnancy.

The pregnancy is then followed-up against medical advice, on Labetalol and magnesium sulphate. A cesarean section is done in the 28th week in a context of IUGR (Fig. 3), pathological uterine Doppler with notching, pathological umbilical Doppler with absence of diastole and pathological cerebral Doppler 
with vasodilation (Fig. 5). Birth of a 500-g female, dies on the 43rd day of life.

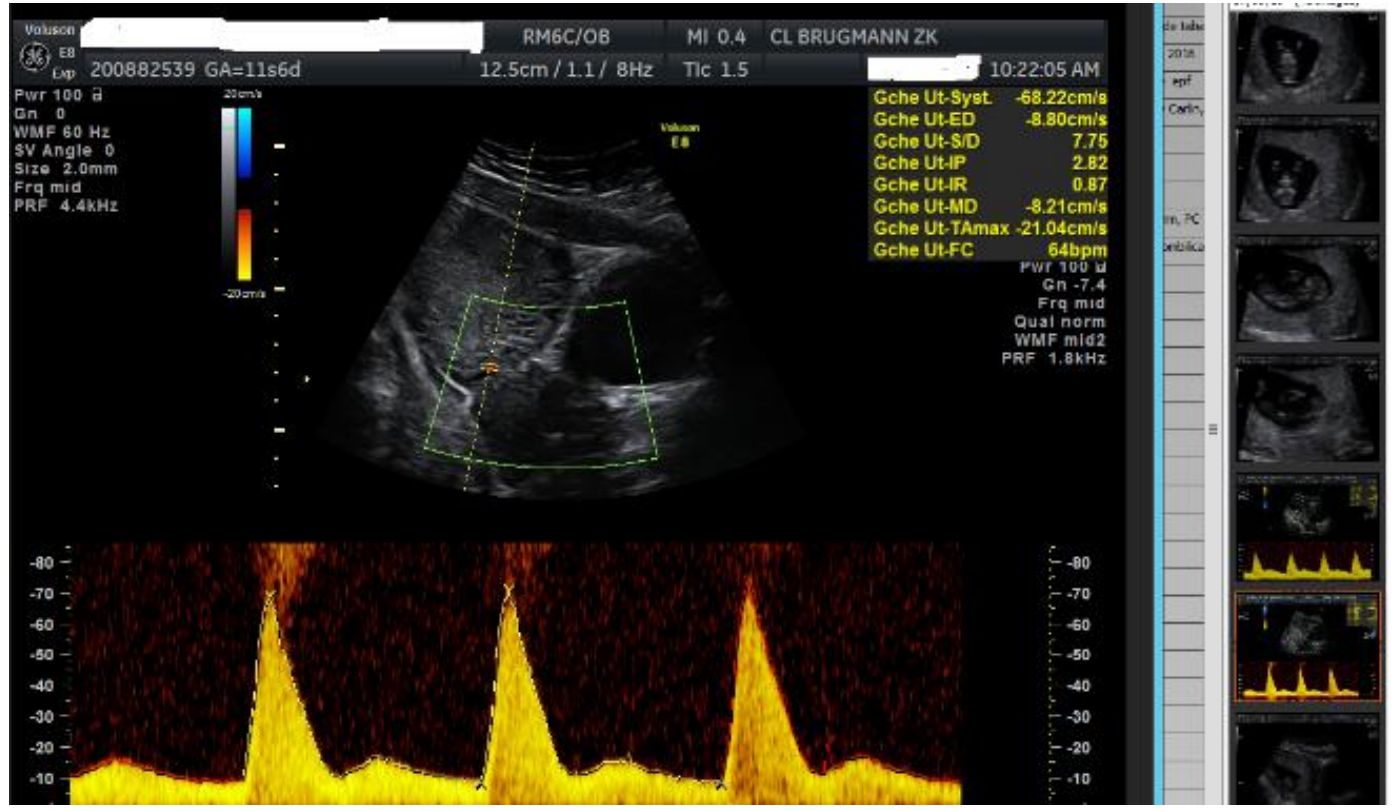

Fig. 1 Pathological unterin Doppler at T1; IP: 2.82.

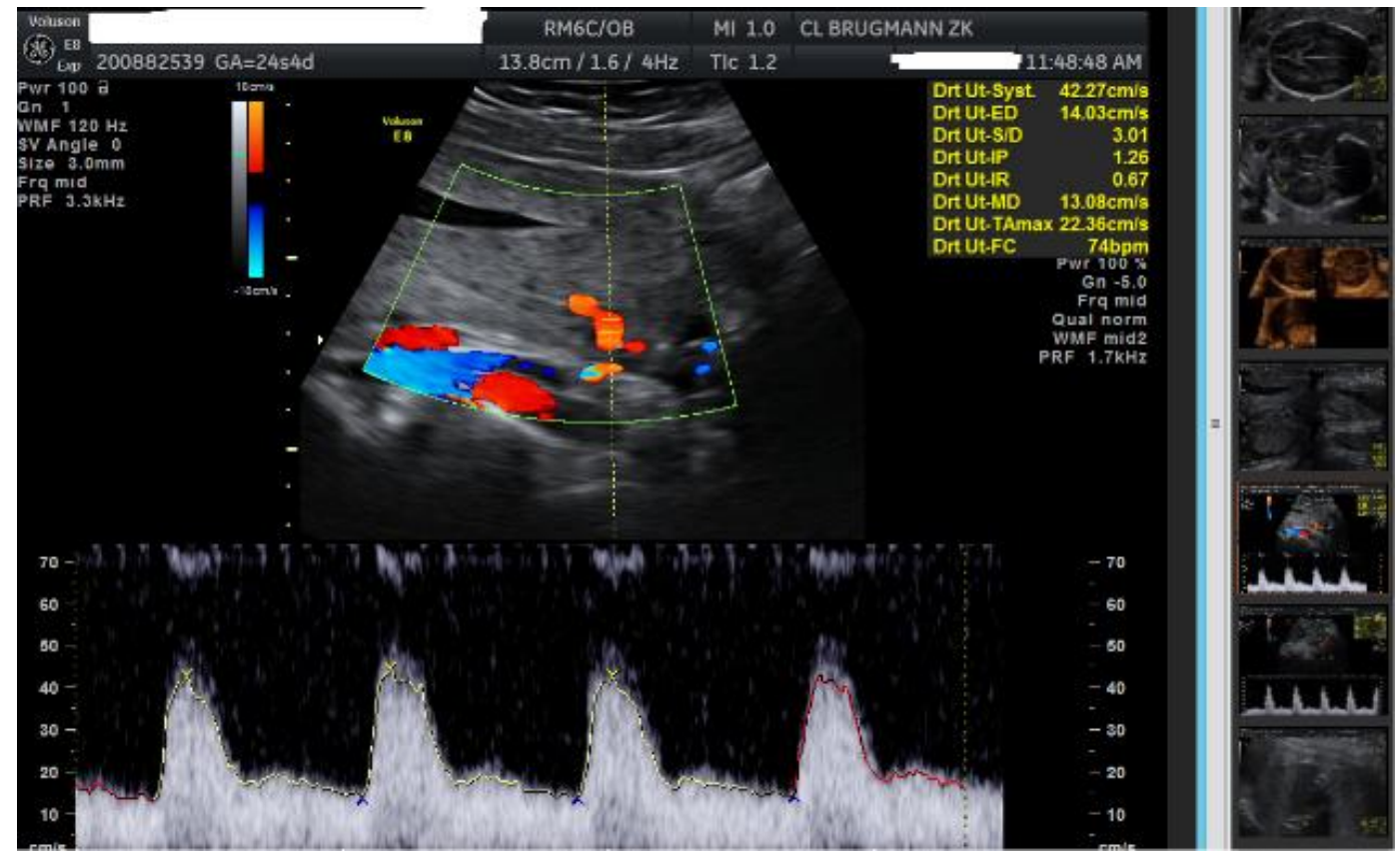

Fig. 2 Pathologica unterin Doppler with Notch at T2; IP:1, 26. 
Age gestasianel 27 semsines +4 jours

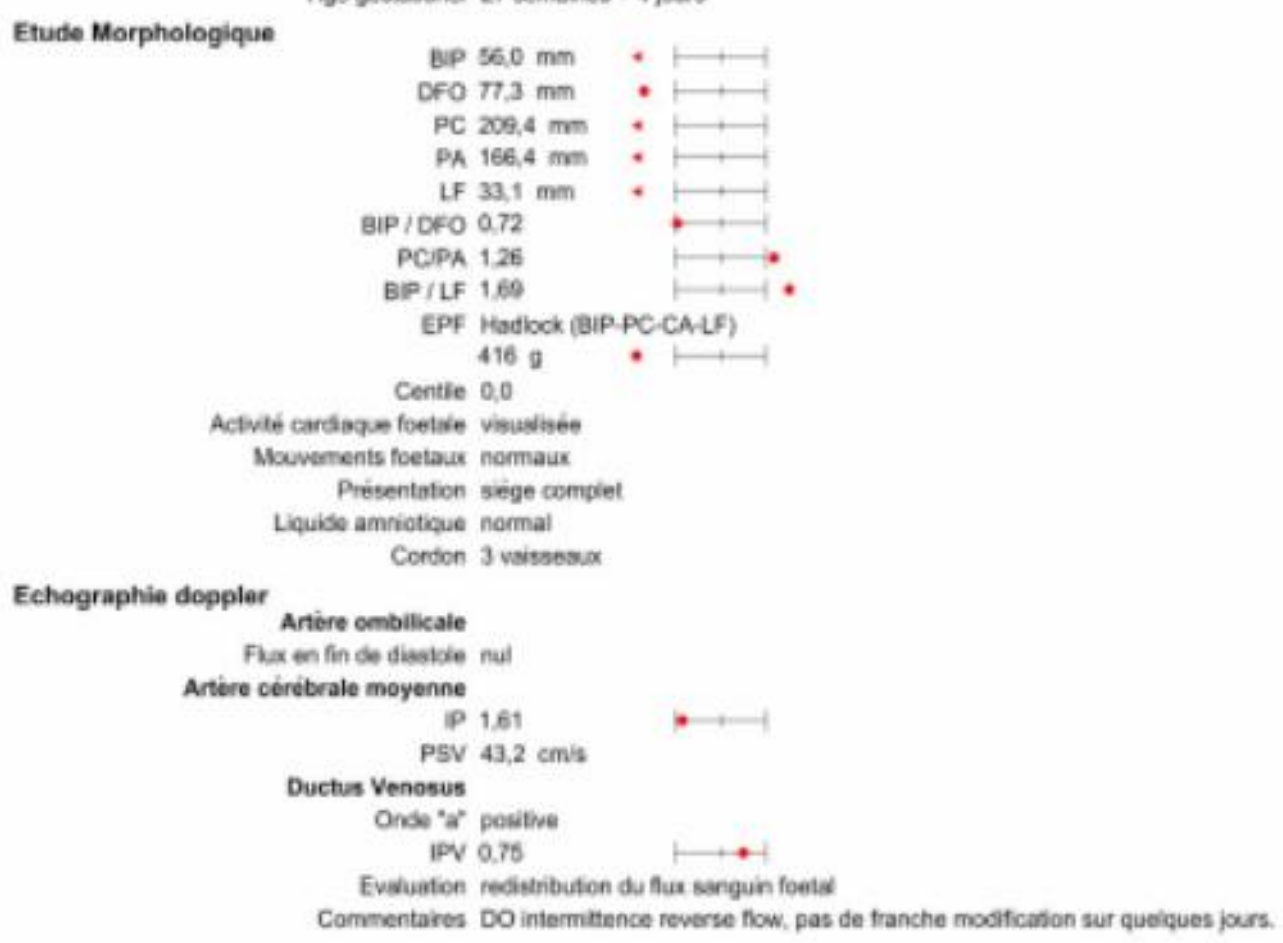

Hospitalisete pour RCIU severe et pret

Grossesse monototale évolutive de 27 sa et 4 jours.

Bonne vitaitè fotale.

Liquide emnictique dis linile mais stable - L.A.7.25cm = P5

Doppler foetaux stabies

Croissance $<500 \mathrm{gr}$

Fig. 3 Intra-uterin growth retardation.

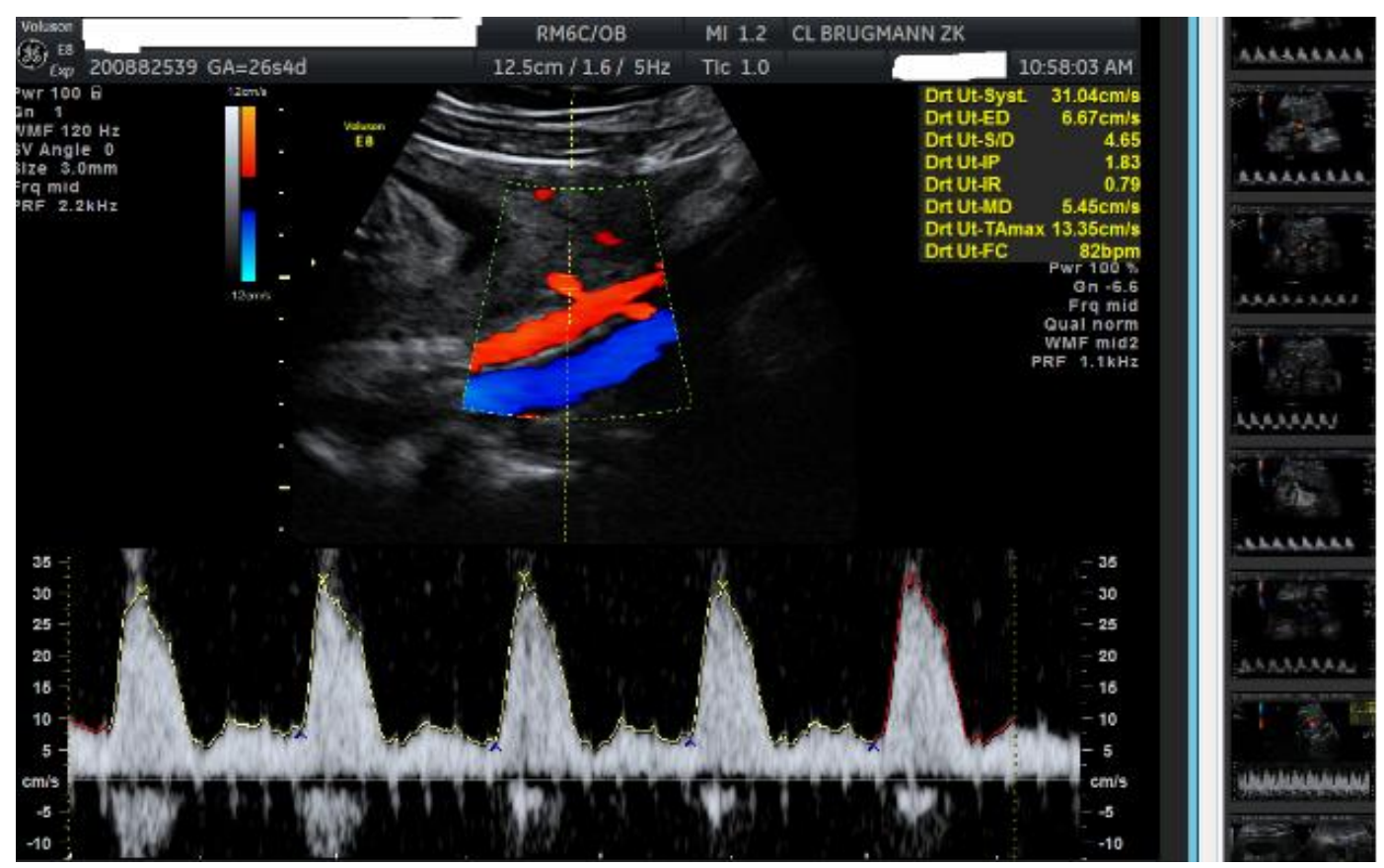

Fig. 4 Pathological unterin Doppler with Notch at T2; IP: 1,83. 


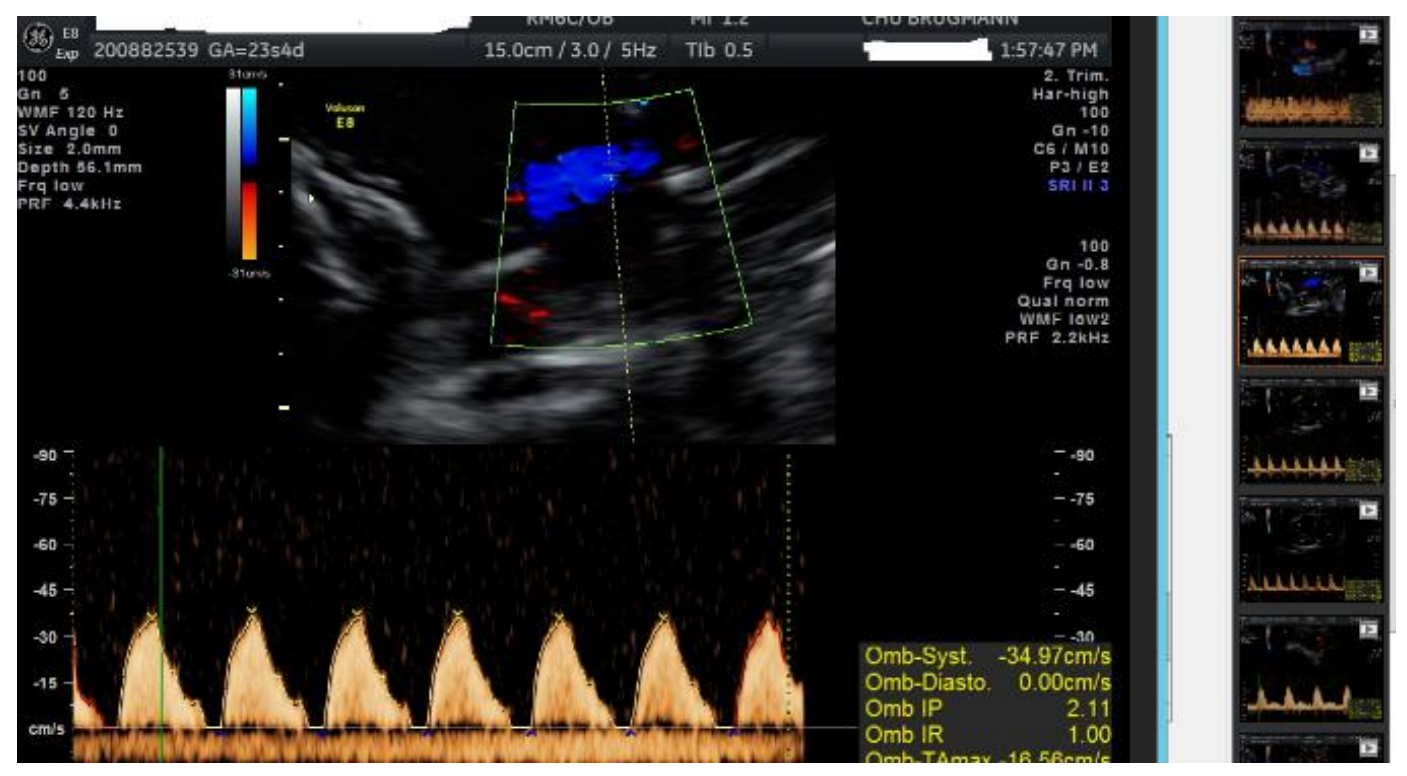

Fig. 5 Pathological umbilical Doppler, absence of diastole IR:1.

\section{Conclusions}

Sperm donation is a risk factor for severe preeclampsia. In our case study, the use of one same donor did not hinder the reoccurrence of the disease. Cryoconvertion of gametes must be envisaged before chemotherapy, as described in scientific literature.

\section{References}

[1] Kyrou, D., et al. 2010. "Is the Use of Donor Sperm Associated with a Higher Incidence of Preeclampsia in Women Who Achieve Pregnancy after Intrauterine Insemination?" Fertil Steril 93: 1124-7.

[2] Collège National des Gynécologues and Obstétriciens Français. 2010. 34 Journée Internationale, Paris 8-10 décembre.

[3] Dekker, G. A., et al. 1998. "Immune Maladaptation in the Etiology of Pre-eclampsia: A Review of Corroborative Epidemiologic Studies." Obstet Gynecol Surv. 53 (6): 377-82.

[4] Peters, B., et al. 2004. "Effect of Heterosexual Intercourse on Mucosal Alloimmunisation and Resistance to HIV-1
Infection." Lancet 363: 518-24.

[5] Marti, J. J., et al. 1977. "Immunogestosis: A New Etiologic Concept of Essential EPH Gestosis, with Special Consideration of the Primigravid Patient." Am J Obstet Gynecol 128: 489-93.

[6] Klonoff-Cohen, H. S., et al. 1989. "An Epidemiologic Study of Contraception and Preeclampsia." JAMA 262: 3143-7.

[7] Saftlas, A. F., et al. 2003. "Abortion, Changed Paternity, and Risk of Preeclampsia in Nulliparous Women." Am J Epidemiol 157: 1108-14.

[8] Einarsson, J. I., et al. 2003. "Sperm Exposure and Development of Pre-eclampsia." Am J Obstet Gynecol 188: 1241-3.

[9] Gonzalez-Comadran, M., et al. 2014. "The Impact of Donor Insemination on the Risk of Preeclampsia: A Systematic Review and Meta-Analysis." European Journal of Obstetrics \& Gynecology and Reproductive Biology 182: 160-6.

[10] Smith, G. N., Walker, M., Tessier, J. L., and Millar, K. G. 1997. "Increased Incidence of Preeclampsia in Women by Intrauterine Insemination with Donor Versus Sperm for Treatment of Primary Infertility." Am J Obstet Gynecol 177: 455-8. 